\title{
More on the 7 Year Economic Cycle and the Bell Normal Curves
}

\section{Paul T E Cusack}

1641 Sandy Point Rd, Saint John, NB, Canada E2K 5E8, Canada

*Corresponding author: Cusack PTE, Independent Researcher, BSc E, DULE, 1641 Sandy Point Rd, Saint John, NB, Canada E2K 5E8, Canada, Tel: (506) 214-3313; E-mail: St-michael@hotmail.com

Received date: January 09, 2017, Accepted date: January 24, 2017, Published date: January 30, 2017

Copyright: (c) 2017 Cusack PTE. This is an open-access article distributed under the terms of the Creative Commons Attribution License, which permits unrestricted use, distribution, and reproduction in any medium, provided the original author and source are credited.

\section{Abstract}

Here is a paper on mathematical economics that provides a solution to the old question as to why the economy goes through a 7-year cycle. The answer lies in astrotheology mathematical physics. The Bell Normal Curve is used to explain this phenomenon. The viscous forces in the economy, whatever they may be, must be overcome by the inertial forces. Further study of these forces should be undertaken so that the negative impact of the cycle can be overcome.

Keywords: Bell Normal Curve; Economic cycle; Savings rate; Astrotheology; Mathematics

\section{Introduction}

It has been known for some time that the economy goes through a complete economic cycle approximately every 7 years. In a previous paper, I showed that the root cause for this phenomenon is demographics and the fertility of women. Having children necessitates spending. In this paper, we look at the and its equation, apply mathematics from Astrotheology Physics to try to understand why it takes 7 years to come to a resolution of a recession. The answer lies in the inertial forces overcoming the viscous forces as found in the Reynold's number. We begin with the Bell Normal curves [1-2].

\section{Bell Normal Curves}

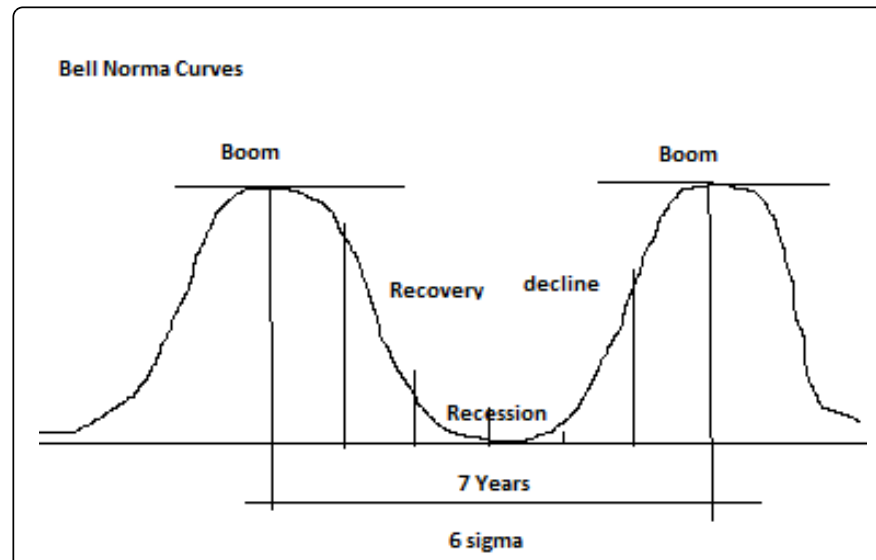

Figure 1: Bell Normal Curve showing the economic cycle.

The equation for the Bell Normal Curve is:

$\Phi=1 /(2 \pi) \int e-t^{2} / 2$
Take the derivative,

$\Phi^{\prime}=1 /(2 \pi) e-t^{2} / 2$

$6=1 /(2 \pi) e-t^{2} / 2$

$\mathrm{t}=2.6943 \sim 2.7=\mathrm{e} 99.63 \% \mathrm{e} 1$

$-\mathrm{t}^{2} / 2=6$

$\mathrm{t}=\sqrt{ } 12=3.46$

$2 \mathrm{t}=6.9282 \sim 7$ years or 1 cycle

$\mathrm{Re}=$ Inertial Forces/Viscous forces

$\mathrm{Re}=\rho \mathrm{v} /=$ density * velocity/Poission's ratio

We know from Astrotheology physcs that $\mathrm{Re}=0.403$

$\operatorname{Re}=(0.127)(\sin 1) /(0.27)$

$=1 / 25=1 /(8 \pi)$

$=1 /$ Period $\mathrm{T}$

Since $1 \mathrm{rad}=0.4$ of a cycle, and $\mathrm{Re}=0.403$,

$=1 /[(1 /(2 \pi))(2 \pi)]$

$=1$

The Viscous forces in the economy equal the inertial forces at the "boom".

\section{Reynold's Number}

$\mathrm{Re}=\mathrm{IF} / \mathrm{VF}$
Density=Mass $/$ Volume $=\rho=0.126$
$v=0.27$
$\mathrm{Re}=\rho v / v$
$\mathrm{v}=\mathrm{a}=0.8415=\sin 1 \mathrm{rad} .=\sin \mathrm{t}=\sim 6 \sigma / 7$ tears
$\mathrm{Re}=(0.1272)(0.8415) / 0.27)=0.396 \sim 0.4=\mathrm{Re}$
$\operatorname{Re}=0.4=1 /[2 \pi]$
$=1 / 253=1 /$ Period $\mathrm{T}=\mathrm{t}$


Citation: Cusack PTE (2017) More on the 7 Year Economic Cycle and the Bell Normal Curves. J Glob Econ 5: 231. doi: 10.4172/2375-4389.1000231

Page 2 of 2

$\mathrm{t}=1 \mathrm{rad} /(2 \pi)=0.4$ of a cycle

$\mathrm{t}=\operatorname{Re}$

Now

$\mathrm{e} 6=0.403=\mathrm{Re}=\mathrm{t}$

So the energy in the economy, when the $\mathrm{Re}=1$, or viscous overs inertial forces, is at $\mathrm{t}=6 \sigma=7$ years.

\section{Savings Rate}

$$
\begin{aligned}
& \Phi ;=1 /(2 \pi) \text { e- } \mathrm{t}^{2} / 2 \\
& 7 \text { years } / 6 \sigma=360^{\circ} \\
& 7 / 60^{\circ}=1.167=1 /(2 \pi) \mathrm{e}-\mathrm{t}^{2} / 2 \\
& 7.33=\mathrm{e}-\mathrm{t}^{2} / 2 \\
& \operatorname{Lnn}(7.33)=-\mathrm{t}^{2} / 2 \\
& \mathrm{t}=2 \\
& \text { Ln } 2=0.1353 \sim \text { Savings }
\end{aligned}
$$

Now the Savings=Investments, or $\mathrm{S}=\mathrm{I}$

$S=1 / 7=14.29 \%$

$1-\mathrm{S}=0.8571=\sin 59^{\circ}$

$360^{\circ} / 59^{\circ}=61.0^{\circ}$

$\sin 61^{\circ}=0.8746$

$1-0.8746=0.1254$

$=1 / 7.97 \sim \mathrm{S}=\mathrm{I}$

$\sin 60^{\circ}=0.866$

$1-\sin 60^{\circ}=0.134 \sim 0.1353$ or 7.7 years
So, an economic cycle is about 7 years.

$\Phi^{\prime}=6 \sigma / 7$ years $=1 /(2 \pi) \mathrm{e}-\mathrm{t}^{2} / 2$

$0.8571=1 /(2 \pi) \mathrm{e}-\mathrm{t}^{2} / 2$

$0.8751(2 \pi)=\mathrm{e}-\mathrm{t}^{2} / 2$

$5.4984=\mathrm{e}-\mathrm{t}^{2} / 2$

$\operatorname{Ln}(5.4984)=-\mathrm{t}^{2} / 2$

$\mathrm{t}=0.1358$

Now the cross product from Physics, and E=1/t

$\mathrm{S}=|\mathrm{E}||\mathrm{t}| \sin \mathrm{t}$

$=(1 / 2)(2)(\sin 1 \mathrm{rad})=0.8415$

$=1-\sin 1$

$=0.1585$

$\mathrm{e}-\mathrm{t}=0.1585=1 /(2 \pi)=1 \mathrm{rad}=\mathrm{t}$

\section{Conclusion}

So we see that the Bell Normal Curve adequately explains why the economy takes 7 years to complete one economic cycle. Admittedly, the economy is very complex and there are other factors that influence its duration.

\section{References}

1. Cusack PTE (2016) Astrotheology, Cusack's Universe. Journal of Physical Mathematics 7: 1-8.

2. Cusack PTE (2016) Why the 7 Year Economic Cycle: Boom, Decline, Recession, and Recovery. Journal of Mathematics and Mathematical Sciences. 